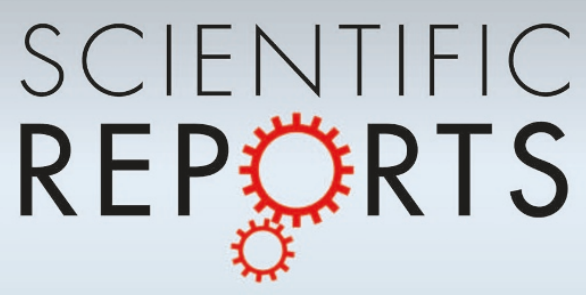

OPEN

SUBJECT AREAS:

HUMAN BEHAVIOUR

POPULATION SCREENING

Received

25 June 2014

Accepted

3 October 2014

Published

11 December 2014

Correspondence and requests for materials should be addressed to W.G. Igaowb@psych. ac.cn)

\section{Development of self-control in children aged 3 to 9 years: Perspective from a dual-systems model}

\author{
Ting Tao, Ligang Wang, Chunlei Fan \& Wenbin Gao
}

Key Laboratory of Mental Health, Institute of Psychology, Chinese Academy of Sciences, Beijing, China.

The current study tested a set of interrelated theoretical propositions based on a dual-systems model of self-control. Data were collected from 2135 children aged 3 to 9 years. The results suggest that (a) there was positive growth in good self-control, whereas poor control remained relatively stable; and (b) girls performed better than boys on tests of good self-control. The results are discussed in terms of their implications for a dual-systems model of self-control theory and future empirical work.

$\mathrm{T}$ he ability to control one's impulses and modulate one's emotional expressions is the earliest and most ubiquitous demand that societies place on children. Moreover, success at many life tasks depends critically on children's mastery of such self-control. Early self-control has a profound and lasting effect on one's life in adulthood. A 32-year longitudinal study indicated that possessing self-control in childhood (defined as 2-10 years of age) predicts physical health, substance dependence, personal finances, and criminal-offending outcomes in adulthood (i.e., there is a self-control gradient) ${ }^{1}$. Moreover, in that study, the effects of children's self-control were separated from the effects of intelligence, social class, and mistakes that were made when the children were adolescents. Similarly, there is evidence that individuals who have strong self-control in early childhood are more successful in school and are more likely to have successful careers and harmonious family relationships in adulthood $^{1,2}$. Furthermore, numerous studies have confirmed that self-control at an early age has positive effects on preschool and middle-childhood academic, social, and emotional ability, as well as on the development of conscience $^{1,2}$. Moreover, self-control can also alleviate behavior, academic, and emotional problems $\mathrm{s}^{3-7}$. Therefore, the form, development, and influence of factors effecting children's early self-control has attracted the attention of developmental psychologists ${ }^{1,8}$.

A majority of the research that has been conducted has explored the development of self-control during two periods: preschool and adolescence. The studies that have focused on the preschool period have tried to determine when self-control emerges and its developmental trajector ${ }^{6,9,10}$. In contrast, because the adolescent period is characterized by sweeping biological, emotional, cognitive, and social changes, the research has focused on topics such as sensation seeking and impulsivity and their relation to risk-taking behavior and psychopathology ${ }^{11-13}$. Thus, there is a significant gap in the research literature representing the period of kindergarten through primary school. This gap is notable because there is a significant change between a child's life in kindergarten versus primary school: in the latter, children are required to regulate their behavior in the classroom and to attend to the teacher's lessons. These environmental changes, in addition to natural maturation, may result in some interesting changes to self-control during this period. Thus, the present study investigated the developmental trajectory of self-control in the period of kindergarten through primary school.

Because self-control is one of the most heavily researched topics in psychology, there are numerous explanatory theories. Recently, a new perspective on self-control has emerged that is informed by advances in psychological science ${ }^{14}$. According to this view, failure at or low levels of self-control may stem from strong impulses, weak control, or a combination of both. Although different researchers have used different terms for these so-called "dual systems" (e.g., "impulse and constraint"15, "effortful control and impulsivity", "reflective and impulsive"16, "X-system and C-system"17, etc.), they all share the same conceptual framework. In Wills and colleagues' studies $^{18,19}$, the dual system of self-control was defined as good self-control and poor control. Individuals with a large amount of good self-control can attend to on-going tasks without rewards, and they can make more careful plans. By contrast, individuals with a large amount of poor control act more directly and impulsively, and they are sensitive to immediately available cues and rewards. There are also neural correlates of these two systems. 
Table 1 | Correlation between age, gender and self-control

\begin{tabular}{|c|c|c|c|c|c|c|c|}
\hline & & 1 & 2 & 3 & 4 & 5 & 6 \\
\hline 1. Age & & - & & & & & \\
\hline \multirow[t]{2}{*}{ 2. Gender } & $r$ & .01 & - & & & & \\
\hline & $p$ & .706 & - & & & & \\
\hline 3. Poor control & $p$ & .480 & .022 & - & & & \\
\hline \multirow[t]{2}{*}{ 4. Good self-control } & $\mathrm{r}$ & .15 & .10 & -.34 & - & & \\
\hline & $p$ & .000 & .000 & .000 & - & & \\
\hline \multirow[t]{2}{*}{ 6. Cognition } & $r$ & .13 & .14 & -.20 & .19 & .43 & - \\
\hline & $p$ & .000 & .000 & .000 & .000 & .000 & - \\
\hline
\end{tabular}

Researches have showed that the good self-control system is based on the prefrontal corte $\mathrm{x}^{20,21}$, whereas the poor self-control system is based on the ventral striatum and amygdala ${ }^{22-25}$. Numerous empirical studies have confirmed that the two systems are distinct constructs and that there is a moderate negative correlation between them. Moreover, several studies have shown that the dual-systems model fits the data significantly better than a uni-dimensional mode ${ }^{3,15,18,19,26,27}$. Because it is likely that studying the two systems jointly will enable a more precise prediction of self-control outcomes than when each system is studied in isolation, we explored the development of self-control from a dual-systems perspective in children aged 3 to 9 years.

\section{Results}

Correlation between variables. The relation between poor control and good self-control was statistically significant $(\mathrm{r}=-.34, p=$ $.000)$, indicating that the two subscales were moderately correlated and independent (see Table 1). The scores on the two subscales were also moderately correlated with the scores on the TSCRS criterion scale. In addition, the correlation coefficients between the two DSSC subscales and age suggest that good self-control $(\mathrm{r}=.15, p=.000)$ has a closer relationship with age than does poor control (r. $=-.02$, $p=.480)$

The predictive value of age and gender on self-control. In order to investigate the effect of age and gender on children's self-control, taking age and gender as independent variables, good self-control and poor control as dependent variables, respectively, two regression analyses were made. The predictive value of age and gender on selfcontrol was examined by making use of step-wise regression models. The criterion of probability of $\mathrm{F}$ to enter is 0.05 and 0.10 for remove. The regression analysis (see Table 2) corroborates the predictive values of age and gender on the two aspects of self-control (i.e., good self-control and poor control). As can be seen in Table 2, the development of good self-control can be predicted by both age and gender, whereas poor control can be predicted only by gender.

The development of self-control in different age groups. Nonparametric tests were used to analyze the differences between age groups because the data were not normally distributed. A Kindependent Samples test showed that the differences between age groups was significant for good self-control $\left(\chi^{2}(6)=40.02, p=.000\right)$ but not poor control $\left(\chi^{2}(6)=9.03, p=.172\right)$. Post-hoc analysis indicated that, for poor control, there were no differences between adjacent age groups. However, for good self-control, the differences between age groups were not significant except the difference between the ages of 5 and 6 years $(Z=-2.94, p=.000)$. As shows in Figure 1.

In order to analyze the difference between good self-control and poor control in different age groups, a 2-independent Samples Nonparametric Test was used. The results showed that, except for the 3-year-old group, scores on good self-control were significantly higher than those on poor control. To further analyze the effect of age on self-control, we divided the children into two groups: children who were in kindergarten and those who were in primary school. The results showed that primary-school children scored higher on good self-control than those in kindergarten $(3.18 \pm 0.52$ vs. $3.36 \pm 0.61, \mathrm{Z}$ $=-5.89, p=.000)$. However, there was no significant difference between the two groups on poor control $(2.99 \pm 0.46$ vs. $2.97 \pm 0.54$, $\mathrm{Z}=-1.50, p=.134)$.

Gender-related differences in self-control. A 2-independent Samples Nonparametric Test was used to analyze the differences between boys and girls because the data were not normally distributed. As a whole, the results show statistically significant differences between boys and girls for both good self-control and poor control (see Table 3). Specifically, girls scored higher than boys on good self-control and lower than boys on poor control. With respect to age groups, girls scored higher than boys at 3,8 , and 9 years on good self-control, but there were no differences between boys and girls on poor control.

\section{Discussion}

It can clearly be seen from the results of the present study that the dual systems of self-control had different developmental curves. It was shown that, during the ages of 3-9 years, children's poor control system remained relatively stable, whereas there was improvement in the good self-control system between the ages of 5 and 6 years. Further analysis showed that kindergartners and primary-school students differed on good self-control rather than poor control. This developmental trajectory is consistent with previous studies that have indicated that levels of self-control increase from early to middle childhood ${ }^{28-30}$. Studies on brain development have shown that the frontal lobe has significant growth from the ages of 5 to 7 years and that the myelination of nerve fibers is completed gradually during this period ${ }^{31}$, providing physiological evidence for the results of our

Table $2 \mid$ Results of a stepwise regression analysis predicting the variance in self-control attributable to age and gender

\begin{tabular}{llcccrrr} 
Subsystem & Predictor & Beta & SE & Standardized Beta & $t$ & \multicolumn{1}{c}{$t$} \\
\hline Good self-control & age & .05 & .01 & .15 & .96 & .000 & .022 \\
Poor control & gender & .12 & .02 & .10 & 4.77 & .000 & .010 \\
\hline
\end{tabular}




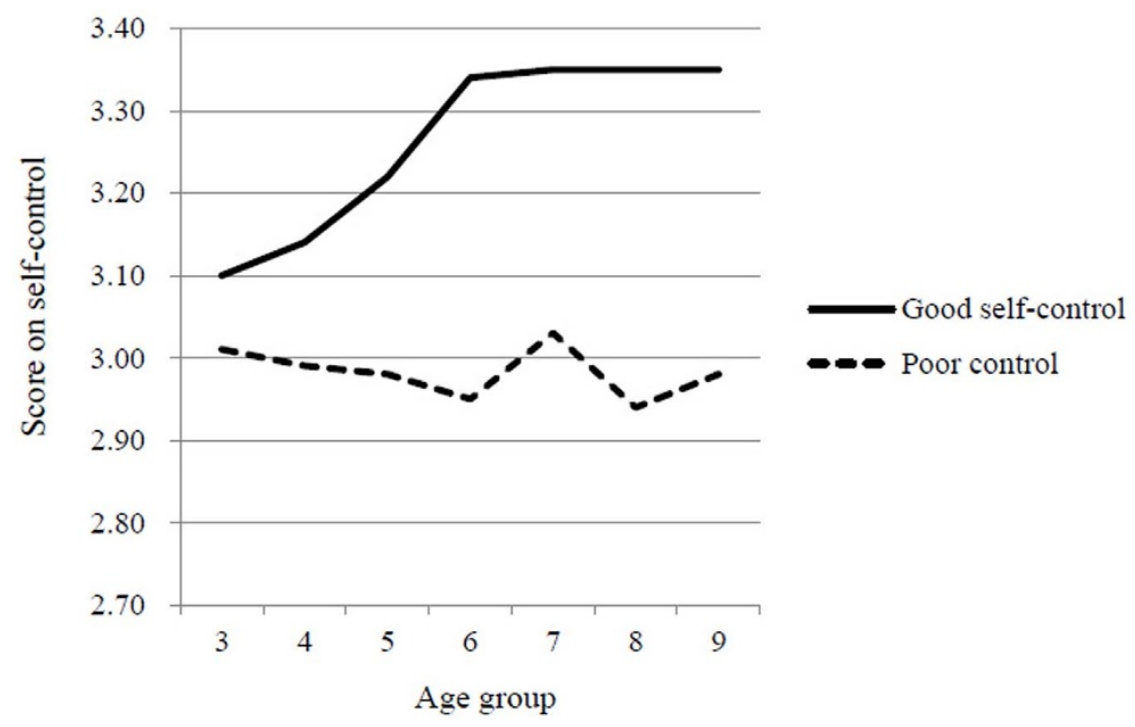

Figure $1 \mid$ described the scores on good self-control and poor control of children aged from 3 to 9 years old.

study to a certain degree. However, at least one study has suggested that children's behavioral regulation remained relatively stable between the ages of 4 to 10 years $^{32}$. To some extent, the current finding that poor control remained stable is consistent with this latter study. That is, although children in this age period can realize that their thoughts can be controlled, they are not always able to do so, which results in impulsive actions.

We also compared the differences between poor control and good self-control across different age groups. The results showed that there was no significant difference between the two systems when children were 3 years old, indicating that children cannot control themselves very well at this age. However, when children were 4 years old, they scored higher on good self-control than poor control, indicating that they can control their impulsivity to some degree. Thus, by synthesizing the information above, it is evident that self-control is not a unidimensional characteristic and that examining the dual systems allows a much more precise understanding of self-control.

Regarding the development of good self-control, in addition to age, the effects of education also must be considered. On the one hand, it can be seen from the current results that children have better good self-control than poor control from the age of 4 years; this indicates that they naturally become prepared for school. On the other hand, when children attend primary school, the education they receive there can promote self-control to some extent. The reason is that the circumstances of primary school are completely different from those of kindergarten. In primary school, children are required to control themselves for up to 40 minutes at a time so that they can attend to the teaching contents. This can be a challenge for some children who have just transitioned from kindergarten, but it may also promote children's good self-control. However, since poor control remained relatively stable, it is not surprising if children are unable to always control themselves (resulting in rule breaking and out-of-seat behavior in the classroom). Therefore, it is necessary for teachers to better understand children's self-control characteristics at this stage in order to achieve a better educational effect.

Gender differences are frequently studied in the self-control literature. Many previous studies on gender differences and self-control have indicated that girls perform better than boys during the preschool stage $e^{9,10,33-36}$. The results in the present study, which showed that girls not only performed better on good self-control but also on poor control than boys, were consistent with these previous studies. However, comparison of boys and girls at each age indicated that girls performed better than boys on good self-control only at the ages of 3, 8 and 9 years. With respect to poor control, boys and girls did not differ at any age. Combining these two findings, it can be inferred that the differences between boys and girls related to self-control are primarily related to good self-control rather than poor control.

Kremon and Block believed that endogenous factors (such as temperament and characteristics of neurons) have a large effect on the development of self-control ${ }^{37}$. The male and female sex chromosomes result in differences in brain and endocrine functioning, which results in different psychological and physical inclinations. All these differences can affect children's behavior directly or indirectly to some degree. In particular, the relationship between testosterone and aggression had been confirmed ${ }^{38,39}$. Hence, compared to girls, boys will show more aggressive behavior, which is a relatively apparent characteristic of poor self-control. Further,

Table 3 | Performance on self-control by gender group

\begin{tabular}{|c|c|c|c|c|c|c|c|c|}
\hline & \multicolumn{4}{|c|}{ Good self-control } & \multicolumn{4}{|c|}{ Poor control } \\
\hline 3 years & $3.01 \pm 0.56$ & $3.17 \pm 0.43$ & -2.12 & .042 & $3.00 \pm 0.45$ & $3.01 \pm 0.44$ & -0.15 & .947 \\
\hline 5 years & $3.19 \pm 0.58$ & $3.26 \pm 0.50$ & -0.87 & .417 & $3.01 \pm 0.46$ & $2.95 \pm 0.48$ & -1.54 & .120 \\
\hline 6 years & $3.32 \pm 0.59$ & $3.37 \pm 0.50$ & -0.67 & .669 & $2.98 \pm 0.54$ & $2.93 \pm 0.50$ & -1.21 & .248 \\
\hline 7 years & $3.31 \pm 0.55$ & $3.39 \pm 0.56$ & -1.23 & .204 & $3.05 \pm 0.51$ & $3.01 \pm 0.48$ & -0.55 & .458 \\
\hline total & $3.21 \pm 0.60$ & $3.33 \pm 0.54$ & -4.42 & .000 & $3.01 \pm 0.50$ & $2.96 \pm 0.51$ & -2.89 & .001 \\
\hline
\end{tabular}


Table $4 \mid$ Age and gender distribution of the sample $(n=2135)$

\begin{tabular}{lccccccc} 
Age group & $3(\mathrm{n}=191)$ & $4(\mathrm{n}=343)$ & $5(\mathrm{n}=357)$ & $6(\mathrm{n}=287)$ & $7(\mathrm{n}=333)$ & $8(\mathrm{n}=360)$ & $9(\mathrm{n}=264)$ \\
\hline Mean $\pm \mathrm{SD}$ & $3.62 \pm 0.27$ & $4.47 \pm 0.28$ & $5.47 \pm 0.28$ & $6.46 \pm 0.27$ & $7.48 \pm 0.28$ & $8.50 \pm 0.28$ & $9.33 \pm 0.23$ \\
Range & $3.00-3.92$ & $4.00-4.92$ & $5.00-5.99$ & $6.00-6.92$ & $7.00-7.96$ & $8.00-8.92$ & $9.00-9.92$ \\
Gender (M/F) & $83 / 108$ & $185 / 158$ & $185 / 172$ & $149 / 138$ & $161 / 172$ & $159 / 201$ & $140 / 124$ \\
\hline
\end{tabular}

society and culture model the core values and behaviors of males and females to some extent. In most societies, females are thought to be more sensitive and caring than males, whereas males are thought to be more aggressive and independent ${ }^{10}$. These stereotypes may also influence differences in self-control between boys and girls. Of course, there is also interaction between genes and cultures. Cross and colleagues made a meta-analysis about studies on sensation seeking ${ }^{40}$, which is also one aspect of self-control. Their results support that men and women differ in their propensity to report sensation-seeking characteristics, which indicating that sex differences in self-control could reflect genetically influenced predispositions interacting with socially transmitted information.

Evolutionary psychology provides an explanation for gender differences in self-control from another perspective. Bjorklund and Kipp reviewed studies that examined gender differences on social, behavioral, and cognitive tasks involving inhibition and found gender differences favoring females most consistently for social tasks (e.g., control of emotions) ${ }^{41}$. Gender differences were somewhat less pronounced for behavioral tasks (e.g., delay of gratification), and weak and inconsistent for cognitive tasks (e.g., conceptual tempo). This pattern was interpreted as consistent with the position that gender differences related to inhibition are relatively domain specific in nature, with women demonstrating greater abilities on tasks related to reproduction and childrearing.

Generally speaking, the dual systems of self-control have different developmental curves in children aged 3 to 9 years. Specifically, the poor-control system remains stable, whereas the good-self-control system improves between the ages of 5 and 6 years. In addition, girls perform better than boys, particularly on good self-control. These findings are especially useful for primary school teachers.

However, there are also some deficiencies in the present study. First, the most notable deficiency is that there is no longitudinal data for the investigation of the developmental trajectory of self-control. Second, self-control is likely to be influenced by a range of other influences (e.g. parenting) while the present study only considered age and sex. Third, the assessments of self-control are depended on other-rating scales, lacking direct assessment of children's self-control, especially physiological assessments. In future studies, we will try to do some following up studies using more assessments under the framework of dual-systems of self-control.

\section{Methods}

Participants. The participants in this study were recruited from six different provinces in China, including Anhui, Fujian, Jilin, Ningxia, Shanxi, and Sichuan, basically covered different types of provinces in the whole country. In each province, at least one kindergarten and one primary school were chosen randomly to take participate in this study. We got a study population composed of 2155 children aged 3-9 years. The data for 20 children were excluded because they were incomplete. Thus, the final sample consisted of 2135 participants. Characteristics of the sample are provided in Table 4.

Measures. The Dual-systems of Self-control Scale for Children (DSSC) $)^{42}$ consists of 23 items across two subscales: good self-control (10 items, e.g., He/She often makes plans before actions.) and poor control (13 items, e.g. He/she thinks that enjoying the moment is more important than planning for the future). Each item is scored on a five-point scale (where $1=$ "not suitable at all" and 5 = "very suitable"), and higher scores indicate higher levels of good self-control and poor control for the good selfcontrol and poor control subscales, respectively. The scale assesses children's selfcontrol in five areas: factors-planning, impulsivity, distractibility, persistence, and poor delay of gratification. Among these areas, factors-planning and persistence belong to good self-control subscale; impulsivity, distractibility, and poor delay of gratification belong to poor control subscale. In the present study, Cronbach's $\alpha$ s were
0.832 and 0.812 for the good self-control and poor control subscales, respectively. Cronbach's $\alpha$ for the overall scale was 0.633 .

The Teacher Self-control Rating Scale (TSCRS) ${ }^{43}$ includes 15 items across two subscales: a cognition dimension (10 items) and a behavior dimension ( 5 items). Each item is scored on a five-point scale (where $1=$ "never" and $5=$ "often"), and higher scores indicate higher levels of self-control. In the present study, Cronbach's $\alpha$ s were 0.800 and 0.663 for the cognition and behavior subscales, respectively. Cronbach's $\alpha$ for the overall scale was 0.816 .

Procedure. The DSSC was administered to parents by class advisers; parents were asked to return the questionnaire to the advisers the next day. The TSCRS was completed by teachers who assessed each child's everyday performance. Before participation, parents and teachers signed informed consent forms. The study was approved by the Ethics Committee of the Institute of Psychology, Chinese Academy of Sciences and methods were carried out in accordance with the approved guidelines.

1. Moffitt, T. E. et al. A gradient of childhood self-control predicts health, wealth, and public safety. Proc. Natl. Acad. Sci. 108, 2693-2698 (2011).

2. Henry, B., Caspi, A., Moffitt, T. E., Harrington, H. \& Silva, P. A. Staying in school protects boys with poor self-regulation in childhood from later crime: A longitudinal study. Int. J. Behav. Dev. 23, 1049-1073 (1999).

3. Eisenberg, N. et al. The relations of effortful control and impulsivity to children's resiliency and adjustment. Child Dev. 75, 25-46 (2004).

4. Eisenberg, N. et al. Longitudinal relations of children's effortful control, impulsivity, and negative emotionality to their externalizing, internalizing, and co-occurring behavior problems. Dev. Psychol. 45, 988-1008 (2009).

5. Eisenberg, N., Smith, C. L. \& Spinrad, T. L. Effortful control: Relations with emotion regulation, adjustment, and socialization in childhood. In Handbook of Self-regulation: Research, Theory, and Applications (eds Vohs, K. D. \& Baumeister, R. F.) pp263-283 (The Guilford Press, New York, 2010).

6. Kochanska, G., Murray, K. T. \& Harlan, E. T. Effortful control in early childhood: Continuity and change, antecedents, and implications for social development. Dev. Psychol. 36, 220-232 (2000).

7. Murray, K. T. \& Kochanska, G. Effortful control: Factor structure and relation to externalizing and internalizing behaviors. J. Abnorm. Child Psych. 30, 503-514 (2002).

8. Rothbart, M. K. \& Rueda, M. R. The development of effortful control. In Developing Individuality in the Human Brain: A Tribute to Michael I. Posner (eds Awh, E., Mayr, U. \& Keele, S.) pp 167-188 (American Psychological Association, Washington, D. C., 2005)

9. Kochanska, G., Coy, K. C. \& Murray, K. T. The development of self-regulation in the first four years of life. Child Dev. 72, 1091-1111 (2001).

10. Yang, L. \& Song, H. Development on preschool children's self-control ability. Stud. Psychol. Behav. 1, 51-56 (2003).

11. Harden, K. P. \& Tucker-Drob, E. M. Individual differences in the development of sensation seeking and impulsivity during adolescence: Further evidence for a dual systems model. Dev. Psychol. 47, 739-746 (2011).

12. Steinberg, L. A dual systems model of adolescent risk-taking. Dev. Psychobiol. 52, 216-224 (2010)

13. Steinberg, L. A Social Neuroscience Perspective on Adolescent Risk-Taking. Dev. Psychobiol 28, 78-106 (2008)

14. Hofmann, W., Friese, M. \& Strack, F. Impulse and self-control from a dualsystems perspective. Perspec. Psychol. Sci. 4, 162-176 (2009).

15. Carver, C. S. Impulse and constraint: Perspectives from personality psychology, convergence with theory in other areas, and potential for integration. Pers. Soc. Psychol Rev. 9, 312-333 (2005).

16. Strack, F. \& Deutsch, R. Reflective and impulsive determinants of social behavior. Pers. Soc. Psychol Rev. 8, -247 (2004).

17. Lieberman, M. D. The X- and C-systems: The neural basis of automatic and controlled social cognition. In Social Neuroscience: Integrating Biological and Psychological Explanations of Social Behavior (eds Harmon-Jones, E. \& Winkielman, P.) pp 290-315 (Guilford Press, New York, 2007).

18. Wills, T. A., Ainette, M. G., Mendoza, D., Gibbons, F. X. \& Brody, G. H. Self control, symptomatology, and substance use precursors: Test of a theoretical model in a community sample of 9-year-old children. Psychol. Addict. Behav. 21, 205-215 (2007)

19. Wills, T. A., Walker, C., Mendoza, D. \& Ainette, M. G. Behavioral and emotional self-control: Relations to substance use in samples of middle and high school students. Psychol. Addict. Behav. 20, 265-278 (2006).

20. Miller, E. K. \& Cohen, J. D. An intergrative theory of prefrontal cortex function. Annu. Rev. Neurosci. 24, 167-202 (2001). 
21. Ochsner, K. N. \& Gross, J. J. The cognitive control of emotion. Trends Cogn. Sci. 9 , 242-249 (2005).

22. Cardinal, R. N., Parkinson, J. A., Hall, J. \& Everitt, B. J. Emotion and motivation: The role of the amygdala, ventral striatum, and prefrontal cortex. Neurosci. Biobehav. R. 26, 321-352 (2002).

23. Delgado, M. R. Reward-related responses in the human striatum. Ann. NY. Acad. Sci. 1104, 70-88 (2007).

24. LeDoux, J. E. Emotion circuits in the brain. Annu. Rev. Neurosci. 23, 155-184 (2000).

25. Schultz, W., Dayan, P. \& Montague, P. R. A neural substrate of prediction and reward. Science 275, 1593-1599 (1997)

26. Wills, T. A. \& Stoolmiller, M. The role of self-control in early escalation of substance use: A time-varying analysis. J. Consult. Clin. Psych. 70, 986-997 (2002).

27. Wills, T. A., Isasi, C. R., Mendoza, D. \& Ainette, M. G. Self-control constructs related to measures of dietary intake and physical activity in adolescents. J. Adolescent Health 41, 551-558 (2007).

28. Block, J. H. \& Block, J. Venturing a 30 year old longitudinal study. Am. Psychol. 61, 315-327 (2006).

29. Vazsonyi, A. T. \& Huang, L. Where self-control comes from: on the development of self-control and its relationship to deviance over time. Dev. Psychol. 46, 245-257 (2010)

30. Raffaelli, M., Crockett, L. J. \& Shen, Y. L. Developmental stability and change in self-regulation from childhood to adolescence. J. Genet. Psychol. 166, 54-75 (2005).

31. Cole, M. \& Cole, S. R. The Development of Children. (New York: W. H. Freeman and Company, 1989).

32. Murphy, B., Eisenberg, N., Fabes, R. A., Shepard, S. \& Guthrie, I. K. Consistency and change in children's emotionality and regulation: A longitudinal study. Merrill-Palmer Quart. 45, 413-444 (1999).

33. Kendall, P. C. \& Wilcox, L. E. Self-control in children: development of a rating scale. J. Consult. Clin. Psych. 47, 1020-1029 (1979).

34. Rothbart, M. K., Ahadi, S. A., Hershey, K. L. \& Fisher, P. Investigations of temperament at three to seven years: The Children's Behavior Questionnaire. Child Dev. 72, 1394-1408 (2001)

35. Rueda, M. R. et al. Development of attentional networks in childhood. Neuropsychologia 42, 1029-1040 (2004).

36. Zhang, P., Liang, Z., Chen, H. \& Zhang, G. The stability and gender difference of children's self-control from 2 to 11 years old. Psychol. Dev. Educ. 5, 463-470 (2012)

37. Kremen, A. M. \& Block, J. The roots of ego-control in young adulthood: links with parenting in early childhood. J. Pers. Soc. Psychol. 75, 1062-1075 (1998).

38. Constantino, J. N. Testosterone and aggression. J. Am. Acad. Child Psy. 34, 535-536 (1995).
39. Constantino, J. N., Grosz, D., Saenger, P., Chandler, D. W., Nandi, R. \& Earls, F. J. Testosterone and aggression in children. J. Am. Acad. Child Psy. 32, 1217-1222 (1993).

40. Cross, C. P., Cyrenne, D.-L. M. \& Brown, G. R. Sex differences in sensationseeking: a meta-analysis. Sci. Rep. 3, 2486 (2013).

41. Bjorklund, D. F. \& Kipp, K. Parental investment theory and gender differences in the evolution of inhibition mechanisms. Psychol. Bull. 120, 163-188 (1996).

42. Wang, L., Xie, D., Fan, C. \& Gao, W. The dual-systems of self-control scale for children: Development, reliability and validity. Chin. J. Behav. Med. Brain Sci. 23, 362-365 (2014).

43. Humphrey, L. L. Children's and teachers' perspectives on children's self-control: The development of two rating scales. J. Consult. Clin. Psych. 50, 624-633 (1982).

\section{Acknowledgments}

This project was supported by the Scientific Foundation of Institute of Psychology, Chinese Academy of Sciences [Y3CX141005] and the National Key Technologies R\&D Program of China [2012BAI36B01].

\section{Author contributions}

T.T. and L.W. designed the experiment. T.T. and L.W. collected and analyzed the data. T.T. drafted the manuscript. L.W., C.F. and W.G. provided critical reversions. All authors approved the final version of the paper for submission.

\section{Additional information}

Competing financial interests: The authors declare no competing financial interests.

How to cite this article: Tao, T., Wang, L., Fan, C. \& Gao, W. Development of self-control in children aged 3 to 9 years: Perspective from a dual-systems model. Sci. Rep. 4, 7272; DOI:10.1038/srep07272 (2014)

(c) (i) $\Theta($ This work is licensed under a Creative Commons Attribution-NonCommercialNoDerivs 4.0 International License. The images or other third party material in this article are included in the article's Creative Commons license, unless indicated otherwise in the credit line; if the material is not included under the Creative Commons license, users will need to obtain permission from the license holder in order to reproduce the material. To view a copy of this license, visit http:// creativecommons.org/licenses/by-nc-nd/4.0/ 